Research Article

\title{
Evaluation and Influencing Factors of Transportation Industry Energy Efficiency of Changjiang Economic Zone
}

\author{
Yi Xu' and Xiaojuan $\mathrm{Li}$ iD $^{2}$ \\ ${ }^{1}$ Business School of Central South University, Changsha 410083, China \\ ${ }^{2}$ School of Business Administration, Hunan University of Finance and Economics, Changsha 410205, China \\ Correspondence should be addressed to Xiaojuan Li; lixiaojuan@hufe.edu.cn
}

Received 18 October 2021; Revised 9 November 2021; Accepted 12 November 2021; Published 26 November 2021

Academic Editor: Daqing Gong

Copyright (c) $2021 \mathrm{Yi} \mathrm{Xu}$ and Xiaojuan Li. This is an open access article distributed under the Creative Commons Attribution License, which permits unrestricted use, distribution, and reproduction in any medium, provided the original work is properly cited.

\begin{abstract}
Changjiang Economic Zone (CEZ) faces the urgent task to promote the energy conservation and emission reduction of the transportation industry. This study constructs an evaluation system for transportation industry energy efficiency (TIEE) and evaluates TIEEs of 11 CEZ provinces in 2000-2017, using the super-slack-based measure (Super-SBM) model containing undesired output. On this basis, the panel data model was adopted to explore the impactors of TIEE. The main results are as follows: CEZ provinces varied significantly in TIEE. In the sample period, Jiangsu, Jiangxi, Zhejiang, Sichuan, Shanghai, and Anhui achieved relatively satisfactory TIEEs; Hunan, Hubei, and Guizhou performed generally on TIEE, calling for some improvement; Chongqing and Yunnan did not perform well, leaving a huge room for improvement. Judging by TIEE trends in the lower reaches, middle reaches, and upper reaches, TIEE of the lower reaches exhibited a U-shaped trend (first decrease and then increase) and TIEEs of the middle reaches and upper reaches did not fluctuate significantly, except for a few years. There was a marked difference between the three regions in TIEE: TIEE in the lower reaches was much higher than that in the middle reaches and upper reaches. In addition, the panel data model demonstrates that TIEE is significantly promoted by economic growth and transportation structure, obviously suppressed by industrial structure, opening-up, and transportation infrastructure, and not clearly affected by government influence or environmental regulation.
\end{abstract}

\section{Introduction}

The transportation industry, covering sectors like highway transport, railway transport, water transport, and air transport, contributes immensely to the development of national economy. This industry links up production with consumption and plays a key role in resource development and utilization, enhancing interregional connections.

Since the reform and opening-up, China has witnessed a rapid development of its transportation industry. In 2017, the total length of railways in service reached $127,000 \mathrm{~km}$, up by $2.4 \%$ from the previous year, and the total length of highways increased to 4.7735 million $\mathrm{km}$, up by $1.67 \%$ from the previous year. Overall, China's transportation industry has reached a high level of development.
However, the boom of transportation industry is realized with growing energy consumption and the emission of a huge amount of carbon dioxide $\left(\mathrm{CO}_{2}\right)$. According to China's National Bureau of Statistics, in 2017, the transportation industry consumed $9.41 \%$ of all the energy consumed in the country. Back in 2000, the transportation industry accounted for $7.61 \%$ of the total energy consumption in China. Therefore, the energy consumption of the transportation industry has been rising continuously. The International Energy Agency (2017) reported that, in 2017, the highway transport in China emitted about 730 million tons of $\mathrm{CO}_{2}$, about $82 \%$ of the total carbon emissions of the transportation industry.

Against this background, the $13^{\text {th }}$ Five-Year Development Plan for Energy Conservation and Environmental Protection of Transportation Industry highlighted the importance for 
the competent department of transportation industry to promote energy conservation and emission reduction in transportation. An important aspect of reducing the energy cost and emissions of transportation industry is to lower the energy consumption and $\mathrm{CO}_{2}$ emissions of transportation.

As the pilot demonstration zone of ecological civilization construction, Changjiang Economic Zone (CEZ) spans across eastern, central, and western China, covering a total area of 2,050,000 $\mathrm{km}^{2}$. CEZ accounts for over two-fifths of people and gross domestic product (GDP) in China and boasts the strongest competitive strength in the country. In recent years, the burgeoning economy of CEZ has stimulated the constant expansion of its transportation industry.

Currently, CEZ accounts for more than $40 \%$ of transportation workers and converted turnover in China. From 2000 to 2017, the fossil energy consumed by the transportation industry in CEZ increased from 31.29701 million tons of standard coal to 168.5621 million tons of standard coal. The annual growth rate is as high as $8.56 \%$. From 2000 to 2018 , the proportion of fossil energy consumption in the CEZ transportation industry in national total increased from $31.56 \%$ to $39.95 \%$, up by $8 \%$ in only 18 years. This means the transportation industry of CEZ consumes $40 \%$ of the energy consumed by the transportation industry across China. It can be said that CEZ pays a huge energy cost to accelerate the development of transportation industry.

The Three-dimensional Transport Corridor Plan (2014-2020) for CEZ predicts that, in 2013-2020, the passenger turnover and freight turnover in CEZ would increase annually at $7.5 \%$ and $6.2 \%$, respectively. The fast annual growths will further push up energy consumption and $\mathrm{CO}_{2}$ emissions. To ensure the sustainable development of CEZ, it is critical to evaluate CEZ energy efficiency scientifically and explore the factors affecting that efficiency.

The academia is paying more and more attention to transportation industry energy efficiency (TIEE). The existing literature on TIEE either focuses on the energy efficiency in a transportation sector (e.g., highway, railway, water, and air transport) or TIEE of a region.

The representative works of sector-specific TIEE research are as follows: Cui et al. [1] adopted the virtual frontier dynamics slack-based measure (SBM) model to evaluate the energy efficiency of 21 airliners around the world in 2008-2012 and found that Malaysian Airlines had the highest overall energy efficiency. Liimatainen and Pöllänen [2] studied the energy efficiency of road freight in Finland during 1995-2009, and observed that the road freight energy efficiency in Finland first increased and then declined in the sample period. Using the virtual frontier dynamic range adjusted measure (RAM) model, Li et al. [3] deduced the energy efficiency of 22 airliners in 2008-2012 and discovered the large gap between these airlines in energy efficiency.

The representative works of regional TIEE research are as follows: Liu and Lin [4] measured TIEE of each province in China during 2000-2015 and found a significant yet narrowing gap between provinces in TIEE. Cui and Li [5] evaluated the provincial transportation energy efficiency in China, using three-stage virtual frontier data envelopment analysis (DEA), and noticed the important impact of transportation structure and management measures on transportation energy efficiency.

The above literature review shows that some scholars have evaluated the energy efficiency of some sectors in transportation, focusing on enterprise-level energy efficiency. All of them discussed the TIEE from the microperspective. Only a few examined the overall energy efficiency of that industry from the macroperspective. There are two major contributions of this research: First, most TIEE evaluation efforts only consider the output of transportation industry and rarely take into account the carbon emitted by the industry through energy utilization. The neglection of this undesired output leads to bias in efficiency evaluation. By contrast, the carbon emissions of the transportation industry are included in our TIEE. Second, the previous regional TIEE research mainly focuses on the entire country, failing to pay sufficient attention to major regions like CEZ. This paper breaks through the traditional paradigm by taking CEZ as the object.

\section{Materials and Methods}

2.1. Super-SBM Model. Currently, stochastic frontier analysis (SFA) and DEA are the most common tools for energy efficiency evaluation. As a typical parametric estimation approach, SFA needs to build a production function containing input and output variables and evaluates the efficiency by estimating the parameters of the variables and testing their significance [6]. However, there is a major defect with SFA: it is only capable of handling multi-input single-output scenarios and unable to process multi-input multi-output problems. Unlike SFA, DEA can deal with problems with multiple inputs and outputs. That is, DEA is more flexible and practical than SFA. As a result, this paper chooses to evaluate CEZ TIEE with DEA.

The earliest DEA models are radial models which were established by Charnes et al. [7] and Banker et al. [8]. Nevertheless, these early models are only suitable for evaluating efficiencies with good output indices. Neither can they adapt to the efficiency evaluation involving bad output indices. To overcome the limitation, many scholars have tried different ways to process bad output indices, namely, transformation of positive attributes, transposition between inputs and outputs, and adoption of directional distance function. These methods can reasonably handle bad output indices. Nonetheless, the efficiency measurements are still biased, owing to the neglection of the slackness of input and output variables.

The efficiency evaluation with bad output indices was eventually realized perfectly, when Morita et al. [9] came up with the SBM model. This typical nonradial model considers the slackness of variables: the efficiency strictly and monotonically decreases with the slackness variation of inputs and outputs. But, the SBM model also has its defect: the efficiencies of multiple decision-making units (DMUs) are often evaluated as 1 (the upper limit), making it impossible to sort the DMUs by efficiency. Therefore, Du et al. [10] further improved the SBM model into Super-SBM 
model, which eliminates the upper limit of DMU efficiencies and enables the ranking of valid DMUs.

The Super-SBM model operates by the following principle: Let there be a production system of $n$ DMUs, each of which receives $\mathrm{O}$ inputs and produces $\mathrm{P}$ desired outputs and $\mathrm{Q}$ undesired outputs. The inputs, desired outputs, and undesired outputs can be, respectively, described by vectors $X=\left(x_{1}, x_{2}, \ldots, x_{n}\right) \in R_{+}^{O}, \quad Y=\left(y_{1}, y_{2}, \ldots, y_{n}\right) \in R_{+}^{P}$, and $B=\left(b_{1}, b_{2}, \ldots, b_{n}\right) \in R_{+}^{Q}$. Then, the collection of possible production scenarios can be expressed as $T=\{(x, y, b): x$ can produce $y$ and $b\}$. Let $\mathrm{DUM}_{j}$ be the $j$-th DMU to be evaluated. Under the above assumptions, the Super-SBM model can be expressed as follows.

Objective function is

$$
\sigma^{*}=\min \frac{1-(1 / O) \sum_{o=1}^{O}\left(s_{o}^{-} / x_{o j}\right)}{1+(1 / P+Q)\left(\sum_{p=1}^{P}\left(s_{p}^{+} / y_{p j}\right)+\sum_{j=1}^{J}\left(s_{q}^{b-} / b_{q j}\right)\right)} .
$$

Constraints are

$$
\begin{aligned}
& \text { s.t. } x_{o j}+s_{o}^{-} \geq \sum_{\substack{i=1 \\
i \neq j}}^{n} x_{i j} \lambda_{i}, \quad o=1, \ldots, O, \\
& y_{p j}-s_{p}^{+} \leq \sum_{\substack{i=1 \\
i \neq j}}^{n} y_{i j} \lambda_{i}, \quad p=1, \ldots, P, \\
& b_{q j}+s_{q}^{b-} \geq \sum_{\substack{i=1 \\
i \neq j}}^{n} b_{i j} \lambda_{i}-, \quad q=1, \ldots, Q,
\end{aligned}
$$

where $\sigma^{*}$ is the efficiency; $x_{o j}$ is the o-th input of the $\mathrm{j}$-th DMU; $y_{p j}$ and $b_{q j}$ are the p-th desired output and $q$-th undesired output, respectively; $\lambda$ is the weight of the DMU; and $s_{o}^{-}, s_{p}^{+}$, and $s_{q}^{b-}$ are the slack variables. If $s_{o}^{-}, s_{p}^{+}$, or $s_{q}^{b-}$ is nonzero, the inputs are redundant, the desired outputs are lacking, or the undesired outputs are redundant. In any of the three cases, the DMU is invalid and the inputs and outputs need to be improved. Only if $s_{o}^{-}=s_{p}^{+}=s_{q}^{b-}=0$, the DMU is valid and the inputs and outputs need no improvement.

2.2. Evaluation System. Proposed by $\mathrm{Hu}$ and Wang [11], total factor energy efficiency (TFEE) fully considers the substitutive relationships between inputs and reflects regional or industry energy use efficiency more accurately and objectively than single-factor energy efficiency. Therefore, this paper decides to examine the energy efficiency of the transportation industry from the angle of TFEE. Referring to Feng and Wang [12], this paper defines TIEE as the ratio of target energy input to actual energy input after reaching the optimal production, without changing the other inputs of the transportation industry, such as labor and capital. By this definition, our TIEE evaluation system was established with three inputs, namely, labor, capital, and energy, and both desired and undesired outputs. Composed of multiple inputs and outputs, the evaluation system reflects the important principle of "total factor," allows the substitution between each energy factor with other factors, and considers undesired outputs. Hence, the evaluation system can accurately characterize the TIEE. All the input and output indices are recorded in Table 1. The meaning of each input and output is explained is given in the table.

2.2.1. Labor Input. In general, the level of labor input can be measured by the number of workers, labor time, or labor quality. However, it is difficult to acquire the data on labor time or labor quality. Therefore, most scholars choose to measure labor input with the number of workers in the industry. Following this train of thought, the authors selected the year-end number of workers in the transportation industry as the substitute variable of labor input.

2.2.2. Capital Input. There are two kinds of capital inputs, namely, capital flow and capital stock. Many scholars take fixed asset investment, an indicator of capital flow, as capital input. But, this capital flow indicator is inconsistent with actual production activities, because fixed asset investment does not consider the cumulative effect of capital input. Hence, this paper chooses to measure capital input with capital stock indicator. Since no data on capital stock is available in relevant statistical yearbooks, Goldsmith's [13] perpetual inventory method (PIM) was adopted to estimate the capital stock of each CEZ province. The capital stock of the $\mathrm{i}$-th CEZ province in year $t$ can be calculated by

$$
K_{i t}=I_{i t}+(1-\delta) K_{i t-1},
$$

where $K_{i t-1}$ is the capital stock of the i-th CEZ province in year $t-1$ and $I_{t}$ is the fixed asset investment of the $i$-th CEZ province in the transportation industry in year $t$. The initial capital stock is a nominal value containing the price factor. To prevent price-induced distortion, the nominal capital stock was deflated to the actual capital stock with 2000 as the base year, using the fixed asset price index.

2.2.3. Energy Input. Since our research targets TIEE, energy input is naturally the core input of our evaluation system. In this paper, the energy input is measured by the energy consumed by the transportation industry in each CEZ province. Note that the energy consumption refers to the energy consumed at the terminals of the transportation industry.

2.2.4. Expected Output. Normally, the energy efficiency of an industry is measured by the product yield or the total output of that industry. In the transportation industry, two types of indices are optional: yield (passenger turnover and freight turnover) or total output (total output of the transportation industry). Among them, passenger turnover and freight turnover merely manifest the movement of transportation vehicles, failing to reflect the economic value 
TABLE 1: TIEE evaluation system.

\begin{tabular}{|c|c|c|c|}
\hline Type & Name & Definition & Unit \\
\hline \multirow{3}{*}{ Inputs } & Labor input & Year-end number of workers in the transportation indu & 10,000 people \\
\hline & Capital input & $\begin{array}{l}\text { Annual actual capital stock of the transportation industry in each CEZ province with } \\
\qquad 2000 \text { as the base year }\end{array}$ & 100 million \\
\hline & Energy input & $\begin{array}{c}\text { Annual terminal energy consumption of the transportation industry in each CEZ } \\
\text { province }\end{array}$ & $\begin{array}{c}10,000 \text { tons of } \\
\text { coal }\end{array}$ \\
\hline \multirow{2}{*}{ Output } & Desired & $\begin{array}{l}\text { Annual actual total output of the transportation industry in each CEZ province with } \\
\qquad 2000 \text { as the base year }\end{array}$ & 100 million \\
\hline & $\begin{array}{l}\text { Undesired } \\
\text { output }\end{array}$ & Annual $\mathrm{CO}_{2}$ emissions of the transportation industry in each CEZ province & 10,000 tons \\
\hline
\end{tabular}

generated by the transportation industry. Therefore, this paper measures the expected output by the total output of the transportation industry, which accurately demonstrates the important effect of transportation development on economic development. Similarly, the total output of the transportation industry contains price factor. To eliminate the negative effect of deflation, the tertiary industry output index was introduced to deflate the total output of transportation industry at current prices to that at comparable prices with 2000 as the base year.

2.2.5. Undesired Output. Undesired output reflects the various pollutants generated in the energy consumption by the transportation industry. In this industry, the pollutants are mainly produced as the transportation vehicles, e.g., cars, ships, and planes, consume energy. Most of these pollutants are gaseous. $\mathrm{CO}_{2}$ is the dominate type of such waste gases, which contribute the greatest to the greenhouse effect. Drawing on the results of Zhou et al. [14] and Zhang et al. [15], this paper defines the $\mathrm{CO}_{2}$ emissions of the transportation industry as the undesired output. However, China's National Bureau of Statistics has not provided any direct data about the $\mathrm{CO}_{2}$ emissions of the transportation industry. Thus, the authors employed the carbon emission estimation method proposed by the Intergovernmental Panel on Climate Change (IPCC) (2006) to estimate the annual $\mathrm{CO}_{2}$ emissions of the transportation industry in each CEZ province, based on the energy consumption and correlation coefficients of that industry. Specifically, the $\mathrm{CO}_{2}$ emissions can be estimated by

$$
\mathrm{CO}_{2}=\sum_{j=1}^{n} E_{j} \times f_{j} \times w_{j} \times z_{j} \times \frac{44}{12},
$$

where $\mathrm{CO}_{2}$ is the $\mathrm{CO}_{2}$ emissions of the transportation industry in each CEZ province; $E_{i}$ is the $\mathrm{j}$-th energy consumed in transportation activities; $n$ is the number of types of energy utilized by transportation activities; $f_{j}, w_{j}$, and $z_{j}$ are the average net calorific value, carbon content per unit calorific value, and carbon oxidation rate of the $j$-th energy, respectively; and 44 and 12 are the molecular weights of $\mathrm{CO}_{2}$ and carbon, respectively.

2.3. Influencing Factors. This paper also aims to identify the factors that greatly affect CEZ TIEE. The transportation industry has a major impact on each sector of the national economy. Thus, the energy consumption of the industry depends heavily on economic, technological, and policy factors. Drawing on the existing research results, this paper selects 7 factors as the main influencers of TIEE (Table 2).

2.3.1. Economic Growth (EG). EG is closely associated with the energy use of the transportation industry. Liddle and Lung [16] and Azlina et al. [17] demonstrated the long-term causality between per-capita GDP and transportation energy consumption, which would clearly influence TIEE.

2.3.2. Industrial Structure (IS). Different industries have different demands for transportation. Unlike primary and tertiary industries, the secondary industry is dominated by industrial sectors, whose development hinges on transportation activities. Therefore, the IS will exert an important influence on the energy consumption of the transportation industry.

2.3.3. Opening-Up (OU). The degree of OU has been increasing in China. With the gradual opening of the car market, foreign capital throngs China's car market, enabling the domestic car industry to thrive. The boom of domestic car industry is accompanied by the rising occupancy of private vehicles, which boosts the energy consumption and $\mathrm{CO}_{2}$ emissions of the transportation industry [18].

2.3.4. Transportation Structure (TS). Chung et al. [19] and $\mathrm{Wu}$ and $\mathrm{Xu}$ [20] proved the significant influence of TS on transportation energy consumption. Each transportation means has its own applicable objects and scope of advantage. Hence, the variation of TS will surely impact the energy consumption and $\mathrm{CO}_{2}$ emissions of the transportation industry. Zhu and Li [21] found that highway transport has a lower fuel economy and higher carbon emissions than railway transport. This means a high proportion of highway transport in all transportation activities hinders TIEE improvement.

2.3.5. Transportation Infrastructure (TI). The mass construction of TI generally enhances the density of the transportation network and elevates the transportation intensity. The energy consumption of transportation will rise definitely. Suffice it to say that a large increment of TI 
TABle 2: Meaning of each influencing factor.

\begin{tabular}{lcc}
\hline Name & Definition & Unit \\
\hline EG & Ln (per-capita GDP) & Yuan/person \\
IS & Output of the secondary industry/GDP & $\%$ \\
OU & Actual foreign direct investment (FDI)/GDP & $\%$ \\
TS & Highway freight turnover/total freight turnover & $\%$ \\
TI & The sum of the length of railways in service, the length of inland waterways, and the length of highways/of the & $\mathrm{km} / \mathrm{km}^{2}$ \\
GI & Financial expenditure on transportation industry/total financial expenditure & $\%$ \\
ER & Total investment on industrial pollution control/total industrial output & $\%$ \\
\hline
\end{tabular}

intensifies transportation energy consumption and suppresses TIEE. In this paper, TI is measured by dividing the sum of the length of railways in service, the length of inland waterways, and the length of highways in each CEZ province by the area of that province. This variable was assumed to be negatively correlated with TIEE.

2.3.6. Government Influence (GI). Transportation is a capital-intensive industry involving many sectors, such as railway transport, highway transport, water transport, and air transport. The construction of TI requires a heavy investment in a long cycle. In particular, fixed capital investment must take a large proportion in transportation investment. As a result, it is impossible to invest in Suffice it to transportation industry solely through individual or corporate financing. The strong fiscal support from the government is a must. Therefore, the financial expenditure of the government on transportation sectors will greatly affect TIEE.

2.3.7. Environmental Regulation (ER). There is not yet an agreement on how ER influences energy efficiency. The role of ER could be explained by compliance cost theory, the Porter hypothesis, and uncertainty theory. The specific influence of ER on CEZ's TIEE needs to be further tested in this research.

Considering the mechanism of the above 7 influencing factors, this paper establishes a panel data model about the effects of EG, IS, OU, TS, TI, and GI on TIEE:

$$
\begin{aligned}
Y_{i t}= & \alpha_{i t}+\beta_{1 i t} E G_{i t}+\beta_{2 i t} I S_{i t}+\beta_{3 i t} O U_{i t}+\beta_{4 i t} T S_{i t}+\beta_{5 i t} T I_{i t} \\
& +\beta_{6 i t} G I_{i t}+\beta_{7 i t} E R_{i t}+\mu_{i t},
\end{aligned}
$$

where $i=1,2, \ldots, 11$ is each of the $11 \mathrm{CEZ}$ provinces; $t=$ $1,2, \ldots, 18$ is each year in the 18 -year-long sample period; $Y_{i t}$ is the dependent variable, i.e., TIEE of the i-th CEZ province in year $t ; E G, I S, O U, T S, T I, G I$, and $E R$ are the seven independent variables; $\beta_{1}, \beta_{2}, \beta_{3}, \beta_{4}, \beta_{5}, \beta_{6}$, and $\beta_{7}$ are the coefficients of the independent variables; $\alpha_{i t}$ is a constant; and $\mu_{i t}$ is a random disturbance.

2.4. Data Sources. The above analysis enumerates the numerous variables to be examined in this research. The research objects are the panel data about all CEZ provinces in 2000-2017. The data about the following two sets of variables were collected from China Statistical Yearbooks, China Energy Statistical Yearbooks, and local statistical yearbooks.

2.4.1. Variables in the Super-SBM Model. Year-end number of workers in the transportation industry, total terminal energy consumption in the transportation industry, fixed asset investment in the transportation industry, fixed asset price index, total output of the transportation industry, and tertiary industry output index are the variables in the SuperSBM model.

2.4.2. Variables in the Panel Data Model. Here, the model includes GDP, output of secondary industry, actual FDI, highway freight turnover, total freight turnover, length of railways in service, length of inland waterways, length of highways, area of the province, financial expenditure on the transportation industry, total financial expenditure, investment on industrial pollution control, and total industry output.

\section{Results and Discussion}

3.1. TIEE Measurements. Based on the inputs and outputs of our TIEE evaluation system, this paper imports the relevant data into the Super-SBM model of maxDEA to measure TIEEs of the 11 CEZ provinces. The results in Table 3 show that CEZ provinces differed significantly in TIEE.

Judging by average TIEE, Jiangsu (1.0370), Jiangxi (0.9853), Zhejiang (0.9797), Sichuan (0.9433), Shanghai (0.9412), and Anhui (0.9277) achieved relatively satisfactory TIEEs in the sample period, as their average TIEE was all above 0.9. Most of these provinces belong to the lower reaches of CEZ. Only Anhui, Sichuan, and Jiangxi are located in the middle reaches and upper reaches. The high TIEEs of these provinces are attributable to the following facts: the lower reaches provinces like Jiangsu, Zhejiang, and Shanghai boast a developed economy, a booming transportation industry, and a well-established TI, resulting in a relatively high output of the transportation industry. Despite their moderate EG levels, Anhui, Sichuan, and Jiangxi managed to realize a high output of transportation industry, because their governments attach great importance to the development of transportation. 
TABle 3: Provincial TIEEs in CEZ.

\begin{tabular}{lccccccccccc}
\hline Year & Shanghai & Jiangsu & Zhejiang & Anhui & Jiangxi & Hubei & Hunan & Chongqing & Sichuan & Guizhou & Yunnan \\
\hline 2000 & 1.1082 & 1.2451 & 1.1781 & 0.7672 & 1.0861 & 0.6935 & 0.7686 & 0.7578 & 0.7272 & 0.5872 & 0.5867 \\
2001 & 1.0950 & 1.1538 & 1.2103 & 0.8174 & 1.0939 & 0.6912 & 0.7931 & 0.7813 & 0.7736 & 0.5837 & 0.5136 \\
2002 & 1.1347 & 1.1235 & 1.2131 & 0.8656 & 1.0500 & 0.6918 & 0.7821 & 0.8104 & 0.7831 & 0.5742 & 0.4939 \\
2003 & 1.1446 & 1.0537 & 1.1621 & 0.9825 & 1.0405 & 0.6875 & 0.7980 & 0.8989 & 0.8271 & 0.5608 & 0.5430 \\
2004 & 1.1284 & 1.0569 & 1.1645 & 0.9987 & 1.0298 & 0.7407 & 0.8524 & 0.7118 & 0.8844 & 0.5525 & 0.5901 \\
2005 & 1.1707 & 0.8219 & 1.0014 & 1.1282 & 0.8700 & 0.6950 & 0.7573 & 0.7174 & 0.9620 & 0.6385 & 0.5885 \\
2006 & 1.1038 & 0.8654 & 0.8128 & 1.1244 & 0.8654 & 0.6924 & 0.7803 & 0.7135 & 1.0336 & 0.6341 & 0.5626 \\
2007 & 0.7380 & 0.8646 & 0.8182 & 1.1195 & 0.9097 & 0.6838 & 0.7828 & 0.6569 & 1.0100 & 0.6105 & 0.5573 \\
2008 & 0.7031 & 0.8513 & 0.7906 & 1.1222 & 0.9313 & 0.6883 & 0.7700 & 0.6318 & 0.9741 & 0.5652 & 0.5368 \\
2009 & 0.6589 & 1.0509 & 0.8611 & 1.0032 & 1.0232 & 0.7622 & 0.9159 & 0.6589 & 1.0262 & 0.9056 & 0.4573 \\
2010 & 0.7222 & 1.0882 & 0.8913 & 1.0071 & 0.9956 & 0.7592 & 0.9174 & 0.6255 & 1.0121 & 0.8967 & 0.4353 \\
2011 & 0.7034 & 1.1345 & 0.8618 & 0.8459 & 0.9668 & 0.7150 & 0.8793 & 0.5962 & 0.9813 & 0.8742 & 0.4047 \\
2012 & 0.7033 & 1.0838 & 0.8167 & 0.8272 & 1.0480 & 0.7071 & 0.8527 & 0.5845 & 0.8798 & 0.8675 & 0.4177 \\
2013 & 0.7276 & 1.0761 & 0.8730 & 0.8305 & 1.0333 & 0.7796 & 0.8906 & 0.6671 & 0.8766 & 1.0983 & 0.4486 \\
2014 & 0.7948 & 1.0469 & 0.9516 & 0.8643 & 1.0276 & 0.8227 & 0.9070 & 0.6864 & 1.1121 & 1.1246 & 0.4461 \\
2015 & 1.0332 & 1.0578 & 0.9544 & 0.8534 & 1.0001 & 0.8253 & 0.8886 & 0.6632 & 1.1318 & 1.1241 & 0.4572 \\
2016 & 1.1853 & 1.0393 & 1.1151 & 0.7343 & 0.7555 & 0.6201 & 0.6937 & 0.5132 & 0.8080 & 0.4301 & 0.6260 \\
2017 & 1.0866 & 1.0519 & 0.9580 & 0.8065 & 1.0087 & 0.7713 & 1.0012 & 0.6594 & 1.1757 & 1.0883 & 0.4672 \\
Mean & 0.9412 & 1.0370 & 0.9797 & 0.9277 & 0.9853 & 0.7237 & 0.8351 & 0.6852 & 0.9433 & 0.7620 & 0.5074 \\
\hline
\end{tabular}

Hunan (0.8351), Hubei (0.7237), and Guizhou (0.7620) performed generally on TIEE, calling for some improvement. Their TIEEs did not reach the optimal frontier for the following reasons: these provinces witnessed a rapid EG in recent years and large passenger and freight turnovers, both of which contribute to $\mathrm{CO}_{2}$ emissions.

TIEEs of Chongqing (0.6852) and Yunnan (0.5074) came at the bottom of CEZ. These two provinces both lie in the upper reaches of CEZ. Chongqing is highly urbanized as the only municipality in western China directly under the central government. However, the rugged terrain holds up the transportation efficiency. The daily travel of residents in Chongqing consumes a huge amount of energy and emits lots of $\mathrm{CO}_{2}$. Yunnan also faces an unfavorable geographical environment. Besides, the province is weak in terms of industrial layout and factor input and thus backward in TI construction. Unsurprisingly, the output level of transportation in Yunnan is among the worst in CEZ.

In general, high TIEE provinces mainly appear in the lower reaches of CEZ, while most provinces in the middle reaches and upper reaches have low TIEEs. Therefore, CEZ must fully consider the provincial differences, while promoting energy conservation and emission reduction in the transportation industry.

Based on geographical location and EG level, CEZ could be divided into three major parts: lower reaches, middle reaches, and upper reaches. TIEE trends of CEZ and the three parts are displayed in Figure 1. Except for the CEZ in lower reaches, the lower reaches and the middle reaches had basically consistent TIEE trends: TIEE remained stable, without significant changes, except for the sudden drop in 2016. As for the lower reaches, TIEE exhibited a U-shaped trend (first decrease and then increase).

Furthermore, there was a huge gap between the lower reaches, middle reaches, and upper reaches in TIEE. From 2000 to 2017, the average TIEE of the lower reaches was
0.9860 , far higher than the global average of 0.8480 ; the average TIEE of the middle reaches was 0.8679 , close to the global mean; the average TIEE of the upper reaches was 0.7245 , far below the global mean. Hence, the lower reaches have the highest TIEE, followed in turn by the middle reaches and the lower reaches. Compared with the lower reaches, the middle reaches and upper reaches face a relatively arduous task of saving the energy and reducing the emissions of transportation activities.

3.2. Results of the Panel Data Model. Using Stata 12.0, panel data model (5) was applied to regress the influencing factors of TIEEs in the 11 CEZ provinces during 2000-2017. Two sets of results were obtained under fixed-effects and randomeffects models, respectively. The estimation results (Table 4) show that the Hausman statistic was 46.77 at the significance level of $1 \%$, a sign of the strong individual fixed effects of the model. Hence, the fixed-effects model has a much stronger explanatory power than the random-effects model. For this reason, the variable coefficients in the fixed-effects model were selected to interpret the regression results.

Table 4 suggests that the coefficient of EG was positive, passing the test at the significance level of $10 \%$. This means EG significantly promotes TIEE. The result is consistent with the conclusion of Liu and Lin [4]: per-capita GDP is positively correlated with TIEE. It can be inferred that the steady growth of EG in CEZ not only brings advanced energysaving technologies but also popularizes new energy vehicles. These clearly promote the energy conservation in the transportation industry.

IS exerted a significant positive influence on TIEE at the level of $1 \%$, i.e., a high proportion of the secondary industry in national economy hinders TIEE improvement. As mentioned before, the development of the secondary industry is closely associated with the transportation industry. Being the main components of the secondary industry, the 


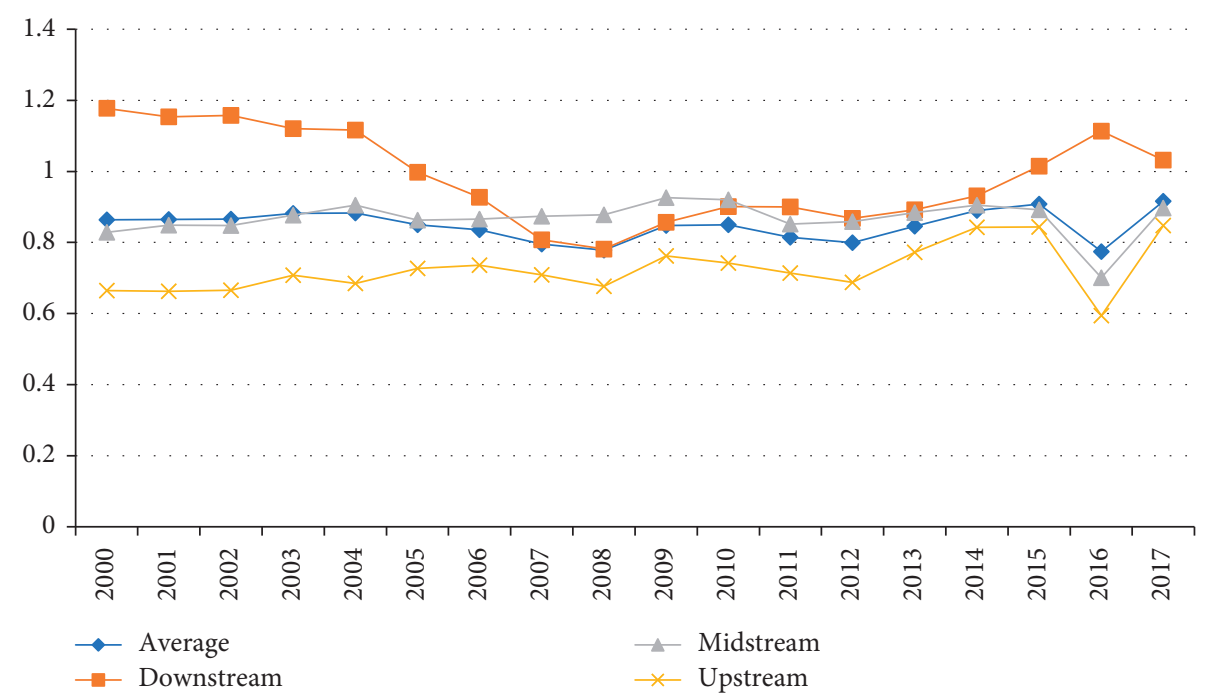

Figure 1: TIEEs of CEZ and its upper reaches, middle reaches, and lower reaches.

TABLE 4: Regression results on TIEE influencing factors.

\begin{tabular}{lcc}
\hline Variable & Fixed effects & Random effects \\
\hline EG & $0.0564^{*}(1.6073)$ & $0.1021^{* * *}(2.7485)$ \\
IS & $-0.6194^{* * *}(-2.8570)$ & $-0.2817(-1.2003)$ \\
OU & $-1.3871^{* *}(-2.0875)$ & $-0.7573(-1.0889)$ \\
TS & $1.1488^{* * *}(5.2454)$ & $0.2894(1.4294)$ \\
TI & $-0.2036^{* * *}(-3.4694)$ & $-0.2007^{* * *}(-3.2900)$ \\
GI & $0.6424(1.1875)$ & $-.2383(-0.4081)$ \\
ER & $6.9883(1.3111)$ & $-2.4298(-0.4165)$ \\
Adj R & 0.2720 & 0.1631 \\
obs & 198 & 198 \\
Hausman & \multicolumn{2}{c}{$46.77^{* * *}$} \\
\hline
\end{tabular}

Note: $T$-test values are in the brackets; ${ }^{*},{ }^{* *}$, and ${ }^{* * *}$ represent the levels of $10 \%, 5 \%$, and $1 \%$, respectively, in the significance test.

industrial sectors provide transportation activities of all sorts of modern vehicles, which stimulate the consumption of fossil energy. Meanwhile, the industrial sectors create lots of job opportunities and increase the demand for logistics. Hence, both passenger and freight turnovers will be increased. Then, fossil energy will be consumed at a faster rate by the transportation industry.

As expected, OU had a significant negative relationship with TIEE. The huge influx of foreign capital injects new vigor into the domestic car industry. At present, every CEZ province sees an obvious rise of car production and sales and an apparent growth in per-capita car ownership. The massive increase in the number of private cars will lead to congestion and cause serious pollution to the environment.

TS significantly promotes TIEE, which is contrary to our expectation. This result comes from China's new energy vehicle strategy. Since the $11^{\text {th }}$ five-year-plan period, the Chinese government has been iterating the importance of researching, developing, and industrializing new energy vehicles. According to the Annual Report on Industrial Competitiveness of China (2020) No. 9 released by the China Academy of Social Sciences, China now owns more new energy vehicles than any other country. The emergence and proliferation of new energy vehicles gradually weaken the reliance on traditional fossil energy like petroleum, phase out the high-carbon mode of highway transport, and promote the energy conservation and emission reduction of the transportation industry.

The coefficient of TI was negative and significant at the level of $1 \%$, indicating the significant negative effect of TI on TIEE. This result is consistent with our expectation. As mentioned before, the massive construction of TI generally enhances the density of the transportation network and elevates the transportation intensity. The energy consumption of transportation will rise definitely. Achour and Belloumi [22] discovered the significant promoting effect of transportation intensity on the energy consumption of transportation. Moreover, Timilsina and Shrestha [23] manifested that transportation energy intensity is the main contributor to carbon emission growth.

The coefficient of GI was positive but did not pass the significance test. A possible reason is that, although government financial expenditure is an important support to transportation development, excessive GI will crowd out private investment and hinder the market regulation of resource allocation. In addition, local GI is less efficient than private investment. The effect of GI on transportation development is also restrained by low-quality repetitive constructions.

ER did not significantly influence TIEE. This result supports the uncertainty theory mentioned before. The insignificant influence is probably due to the fact that the ER in CEZ is still too weak to exert any substantial effect on the coordination between transportation, EG, resources, and environment.

\section{Conclusions}

The study builds a TIEE evaluation system containing undesired output and measures TIEEs of $11 \mathrm{CEZ}$ provinces in 2000-2017 with the Super-SBM model, which overcomes the 
inability of the SBM model to rank multiple valid DMUs. Next, the regional difference of CEZ TIEEs was examined, and a panel data model was developed to analyze the impactors of CEZ TIEEs. The following are the major findings:

(1) CEZ provinces varied significantly in TIEE. Jiangsu, Jiangxi, Zhejiang, Sichuan, Shanghai, and Anhui achieved relatively satisfactory TIEEs, as their average TIEEs was all above 0.9; Hunan, Hubei, and Guizhou performed generally with average TIEEs between $0.7-0.9$, calling for some improvement; Chongqing and Yunnan did not perform well, with average TIEEs below 0.7 .

(2) On the TIEE trends of CEZ and its three parts, TIEE of the lower reaches exhibited a U-shaped trend (first decrease and then increase) and TIEEs of the middle reaches and upper reaches changed rather consistently: TIEE remained stable, without significant changes, except for the sudden drop in 2016. Furthermore, there was a huge gap between the lower reaches, middle reaches, and upper reaches in TIEE. The lower reaches have the highest TIEE, followed by the middle reaches. The lowest TIEE belongs to the lower reaches.

(3) The panel data model suggests that the estimations by the fixed-effects model are more suitable than those by the random-effects model. Specifically, TIEE is significantly promoted by EG and TS, obviously suppressed by IS, OU, and TI, and not clearly affected by GI or ER.

\section{Data Availability}

The data used to support the findings of this study are available from the corresponding author upon request.

\section{Conflicts of Interest}

The authors declare that they have no conflicts of interest regarding the publication of this paper.

\section{Acknowledgments}

This work was sponsored in part by National Social Science Foundation of China: Research on the Behavior and Dynamic Incentive Mechanism of Cross Organizational Knowledge Sharing in the Context of Differentiation (20BGL126).

\section{References}

[1] Q. Cui, Y. Li, C. L. Yu, and Y. M. Wei, "Evaluating energy efficiency for airlines: an application of virtual frontier dynamic slacks based measure," Energy, vol. 113, pp. 1231-1240, 2016.

[2] H. Liimatainen and M. Pöllänen, "Trends of energy efficiency in finnish road freight transport 1995-2009 and forecast to 2016," Energy Policy, vol. 38, no. 12, pp. 7676-7686, 2010.

[3] Y. Li, Y. Z. Wang, and Q. Cui, "Energy efficiency measures for airlines: an application of virtual frontier dynamic range adjusted measure," Journal of Renewable and Sustainable Energy, vol. 8, no. 1, Article ID 015901, 2016.

[4] W. Liu and B. Lin, "Analysis of energy efficiency and its influencing factors in China's transport sector," Journal of Cleaner Production, vol. 170, pp. 674-682, 2018.

[5] Q. Cui and Y. Li, "The evaluation of transportation energy efficiency: an application of three-stage virtual frontier DEA," Transportation Research Part D: Transport and Environment, vol. 29, pp. 1-11, 2014.

[6] W. Meeusen and J. van den Broeck, "Efficiency estimation from cobb-douglas production functions with composed error," International Economic Review, vol. 18, no. 2, pp. 435-444, 1977.

[7] A. Charnes, W. W. Cooper, and E. Rhodes, "Measuring the efficiency of decision making units," European Journal of Operational Research, vol. 2, no. 6, pp. 429-444, 1978.

[8] R. D. Banker, A. Charnes, and W. W. Cooper, "Some models for estimating technical and scale inefficiencies in data envelopment analysis," Management Science, vol. 30, no. 9, pp. 1078-1092, 1984.

[9] H. Morita, K. Hirokawa, and J. Zhu, "A slack-based measure of efficiency in context-dependent data envelopment analysis," Omega, vol. 33, no. 4, pp. 357-362, 2005.

[10] J. Du, L. Liang, and J. Zhu, "A slacks-based measure of superefficiency in data envelopment analysis: a comment," European Journal of Operational Research, vol. 204, no. 3, pp. 694-697, 2010.

[11] J. L. Hu and S. C. Wang, "Total-factor energy efficiency of regions in China," Energy Policy, vol. 34, no. 17, pp. 3206-3217, 2006.

[12] C. Feng and M. Wang, "Analysis of energy efficiency in China's transportation sector," Renewable and Sustainable Energy Reviews, vol. 94, pp. 565-575, 2018.

[13] R. W. Goldsmith, "A perpetual inventory of national wealth," In Studies in Income and Wealth, vol. 14, no. 1, pp. 5-61, 1951.

[14] G. Zhou, W. Chung, and X. Zhang, "A study of carbon dioxide emissions performance of China's transport sector," Energy, vol. 50, pp. 302-314, 2013.

[15] N. Zhang, P. Zhou, and C. C. Kung, "Total-factor carbon emission performance of the Chinese transportation industry: a bootstrapped non-radial malmquist index analysis," $R e$ newable and Sustainable Energy Reviews, vol. 41, pp. 584-593, 2015.

[16] B. Liddle and S. Lung, "The long-run causal relationship between transport energy consumption and GDP: evidence from heterogeneous panel methods robust to cross-sectional dependence," Economics Letters, vol. 121, no. 3, pp. 524-527, 2013.

[17] A. A. Azlina, S. H. Law, and N. H. Nik Mustapha, "Dynamic linkages among transport energy consumption, income and CO2 emission in Malaysia," Energy Policy, vol. 73, pp. 598606, 2014.

[18] R. G. Mishalani, P. K. Goel, A. M. Westra, and A. J. Landgraf, "Modeling the relationships among urban passenger travel carbon dioxide emissions, transportation demand and supply, population density, and proxy policy variables," Transportation Research Part D: Transport and Environment, vol. 33, pp. 146-154, 2014.

[19] W. Chung, G. Zhou, and I. M. H. Yeung, "A study of energy efficiency of transport sector in China from 2003 to 2009," Applied Energy, vol. 112, pp. 1066-1077, 2013.

[20] H.-M. Wu and W. Xu, "Cargo transport energy consumption factors analysis: based on LMDI decomposition technique," IERI Procedia, vol. 9, pp. 168-175, 2014. 
[21] X. Zhu and R. Li, "An analysis of decoupling and influencing factors of carbon emissions from the transportation sector in the Beijing-Tianjin-Hebei area, China," Sustainability, vol. 9, no. 5, p. 722, 2017.

[22] H. Achour and M. Belloumi, "Decomposing the influencing factors of energy consumption in Tunisian transportation sector using the LMDI method," Transport Policy, vol. 52, pp. 64-71, 2016.

[23] G. R. Timilsina and A. Shrestha, "Transport sector $\mathrm{CO}_{2}$ emissions growth in Asia: underlying factors and policy options," Energy Policy, vol. 37, no. 11, pp. 4523-4539, 2009. 